\title{
Online news reports as a source of data on the occurrence and frequency of stowaway reptiles and amphibians entering Great Britain
}

\author{
STEVEN J.R. ALLAIN* \& DAVID J. CLEMENS
}

Cambridgeshire \& Peterborough Amphibian and Reptile Group

*Corresponding author e-mail: steveallain@live.co.uk

\section{INTRODUCTION}

Intro vect troduced species threaten biodiversity globally by acting as vectors of disease, sources of competition, and as predators of native species (Manchester \& Bullock, 2000; Young et al., 2017). One way in which species may be introduced to a new area outside of their natural range (particularly in the case of islands) is as stowaways with goods in trade or with people (Chapple et al., 2013). This is most commonly thought to occur in animals (particularly vertebrates) but plants may also be dispersed in this way (Pyšek et al., 2011; Tomes et al., 2020). If the stowaways find themselves in a suitable climate then they may become established and subsequently threaten native species (Chapple et al., 2013). This is not always the case as some stowaways enter hostile environments or the number of individuals needed to found a viable population never arrives; this number depends on the species (Traill et al., 2007).

There is a history of stowaway animals becoming established in Great Britain. It is believed that midwife toads (Alytes obstetricans) were first introduced to a garden nursery in Bedford in packing cases of ferns and other plants from southern France (Smith, 1949). Sites of cargo importation such as ports are often colonised by shipping stowaways, as is the case with the European yellow-tailed scorpion (Euscorpius flavicaudis) in England (Kent) (Wanless, 1977). Some stowaway species such as the zebra mussel (Dreissena polymorpha) have both ecological and financial impacts, with costs incurred for their removal from water pipes and treatment works (Oreska \& Aldridge, 2011). Whilst it is unlikely that stowaway reptiles and amphibians from the tropics will become established in Britain, those from temperate regions may have a greater chance of success. There is evidence to suggest that wall lizards (Podarcis muralis) can quickly adapt when introduced into cooler areas outside their natural range, such as southern England (While et al., 2015).

Currently, in the primary literature there is very little information on stowaway amphibians and reptiles attempting to enter Britain, although there are occasional reports or summaries (Allain et al., 2017; Clemens \& Allain, 2020). Some historic records do exist (Banks, 1985; Mattison, 1986) but they are too few to enable adequate analysis. An obvious source of such information would be the RSPCA (Royal Society for the Prevention of Cruelty to Animals) but despite our best efforts, they were unwilling to supply the data we need. Consequently, as an alternative we investigated online news for reports of stowaways entering Britain and their countries of origin. With this data we compared the frequency of both different entry pathways and of different countries. It was expected that more reptiles than amphibians would be stowaways due to their greater vagility and robustness to environmental stressors.

\section{METHODS}

Suitable local and national online news reports were identified to establish when stowaways entered Britain and their countries of origin. For a sampling period of a little over 20 years (January 2000 to April 2020) searches were made using three search engines, Google, Bing and Yahoo to remove results bias. A number of keywords were used in combination such as 'stowaway' or 'hitchhiker' with suitable taxa names and the appropriate geographical location (to narrow the search down). An example of a suitable search term would be 'stowaway frog Britain'. To increase the supply of data, a search was also made of the British Newspaper Archive (www.britishnewspaperarchive.co.uk) using the same methods.

When a relevant story was located the following information was noted: the date or year of the report, the species of stowaway and the country of origin. In some instances, the stowaway wasn't identified in the article and so the accompanying photos were used to help determine species (or genus). The same stowaways were sometimes reported by different online news outlets and so care was taken to screen out these duplicates. The entry pathway of stowaways was also recorded as one of three categories: wholesale, retail or holidaymaker. We defined wholesale stowaways as those found in shipping containers or with industrial machinery, retail stowaways as those found in groceries or other goods, and holidaymaker stowaways as those accidentally brought back from holiday in a bag or suitcase.

\section{RESULTS}

Our exhaustive search produced 85 records of 50 different species of stowaway amphibians and reptiles entering Britain 


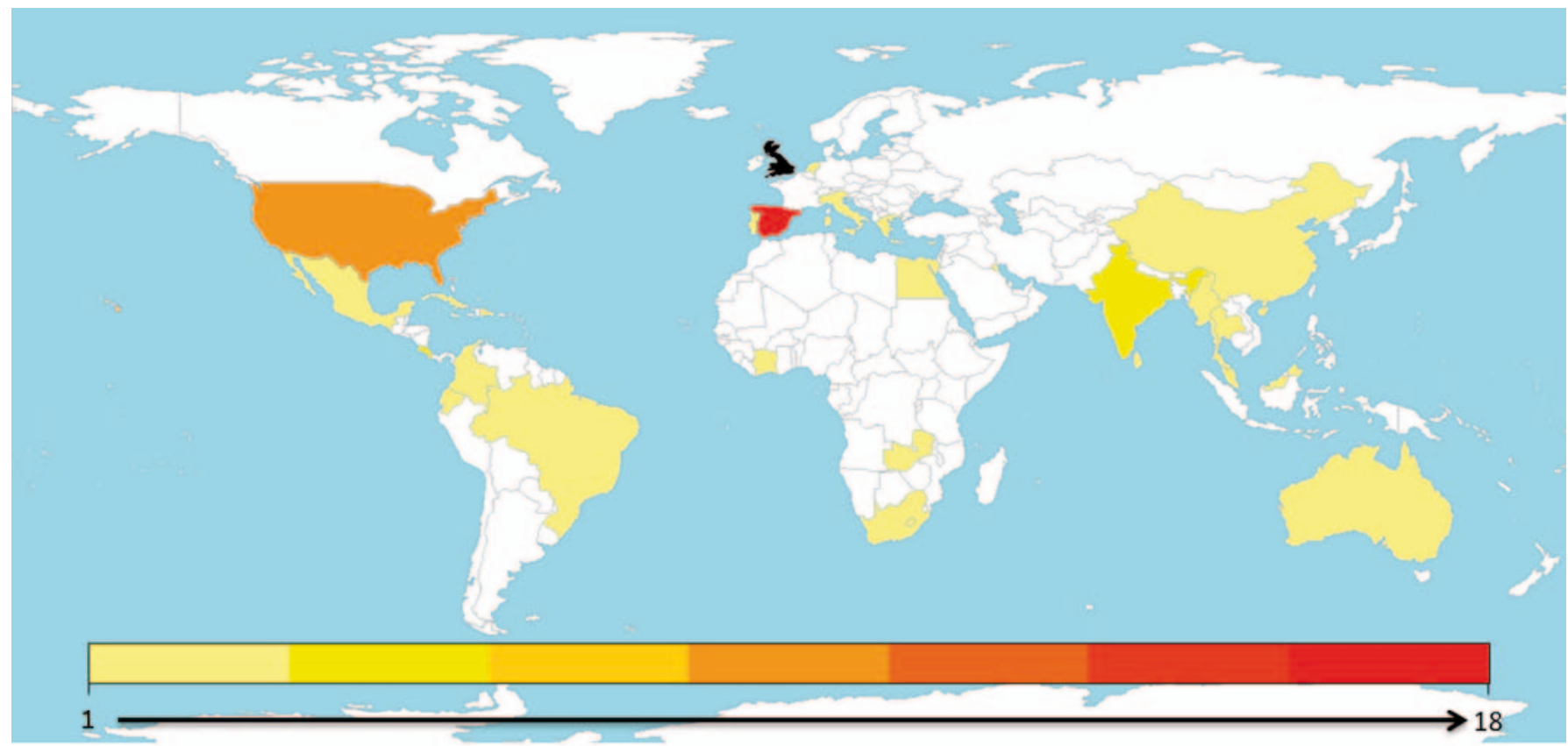

Figure 1. Numbers of online news reports of amphibian and reptile stowaways, by country of origin, entering Britain (black) between 2002 and 2020. The warmer the colour, the higher the number of stowaways.

from 32 countries between 2000 and 2020 (Fig. 1). The number of stowaways reported in the media each year varied widely (Fig. 2) with $73 \%(n=62)$ of cases we recorded being reptiles. The mean number of cases for the period between 2002 and 2016 was three records, significantly lower than that for the three most recent full years (Fig. 2) with 39 out of the 85 reports (46\%) dating from between 2017 and 2019. All records together with links to the online reports are listed in Supplementary Material. There were two cases where the stowaways transported by holidaymakers were exotic aliens. Both species are endemic to the USA - a hognose snake (Heterodon nasicus) that arrived from Kuwait and a Californian kingsnake (Lampropeltis getula californiae) from Spain. These may be escaped pets although the Californian kingsnake is known as an invasive species in the Spanish Island of Gran Canaria (CABI, 2019).

Despite attempts to find records throughout the entire search period, none were found before 2002. All reptiles found during our searches were squamates (lizards and snakes) whereas the majority of amphibian stowaways

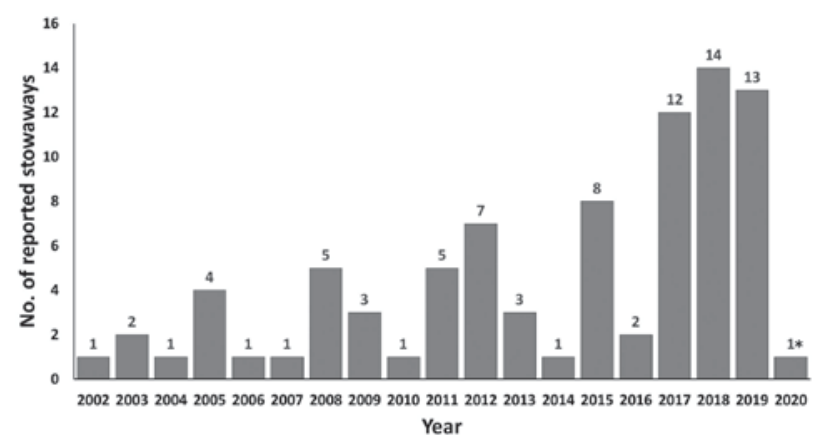

Figure 2. Annual number of online news reports of amphibian and reptile stowaways entering Britain. The years 2000 and 2001 have been omitted since no reports were found for these years. *Not a full calendar year were anurans (frogs and toads). An additional four records were found using the British Newspaper Archive that were missed when using the search engines, due to the fact that these news reports were no longer hosted by their parent organisation. Ten stowaways could not be identified any further than genus level and three could not be identified any further than family level. Older reports lacked photos of the individual animals or the detail of more recent reports which made identification harder. Over half of the stowaways we identified came from just five genera: four lizards Hemidactylus $(n=15)$, Tarentola $(n=11)$, Anolis $(n=6)$, and Podarcis $(n=5)$ and one tree frog Osteopilus $(n=6)$.

The numbers of reports for each of the three potential stowaway entry pathways were statistically significant different (Chi-square goodness of fit, $\chi^{2}=14.971$, $d f=2, p$ $=0.00056$ ) with holidaymakers being the most numerous (Fig. 3).

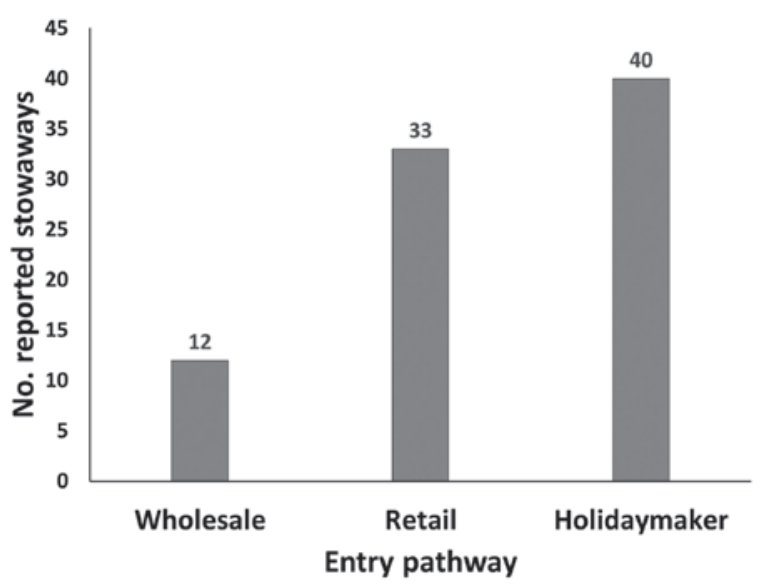

Figure 3. Number of online news reports of amphibian and reptile stowaways by entry pathway into Britain for the years 2002 to 2020 


\section{DISCUSSION}

Our method of investigating the occurrence of stowaway amphibians and reptiles was relatively successful, although the number of reports was lower than expected, especially for the years earlier than 2017. This may be for a number of reasons including the legacy effect of websites, with older pages being deleted or removed from public servers. This indicates that searching for reports of stowaway amphibians and reptiles up to three years after their initial report may continue to yield useful numbers of results.

Despite the reduced number of reports prior to 2017, there were enough cases from which to draw some rudimentary conclusions given that results only provide an estimate and not the true number of stowaways. Our results show that most stowaway amphibians and reptiles came from the USA and Spain (Fig. 1). This is partly due to the fact that both countries are popular holiday destinations with British tourists. Spain also exports a large quantity of fruits and vegetables to Britain, particularly during the winter months which may increase the likelihood of animals becoming stowaways.

The apparent scarcity of reports may be due to the fact that only live animals are reported and that these may be biased by country of origin, the size of the stowaway, and its colour (which will influence detection). Additionally, there is presumably a high rate of mortality associated with stowaways due to the unfavourable conditions in which they find themselves. This may help to explain why more reptiles were recorded than amphibians, as amphibians are generally not as robust as reptiles to factors such as temperature related stress that can lead to an increase in disease susceptibility (Kiesecker, 2011). Not every case will be seen as newsworthy which will also bias the number of reports. Despite this, our results show that between 2002 and 2020, 85 individuals from across the world, representing 18 families of both reptiles and amphibians, entered Britain as stowaways.

Although the evidence suggests that there has been an increase in cases over the past three years, this may be due to reporting bias. For example in 2016 there appeared to be a drop in the number of stowaways (Fig. 2). At this time, other news such as the upcoming EU referendum would have taken precedence over the occurrence of a stowaway reptile being found in a holidaymaker's bag. The scarcity of reports from before this time may be linked to news articles being archived, as they are no longer seen as relevant.

There was no mention in any of the news articles as to whether rehomed stowaways had either been tested for parasites or diseases or were subject to quarantine procedures. None of the stowaways were identified as being likely to establish themselves in Great Britain. Nevertheless, spillover into native populations could have disastrous consequences, furthermore stowaways potentially harbour parasites that are new to science and so have as yet unknown consequences (Smales et al., 2020).

Holidaymakers were apparently the largest contributor to stowaways (Fig. 3). However, wholesale and retail stowaways may be under reported because businesses want to avoid news stories that could be sensationalist (Bombieri et al.,
2008), associated with negative perceptions (Knight, 2018), or that could play on people's fear of amphibians and reptiles (Ceríaco, 2012). Certainly, wholesale movements of goods have for a long time been known as a source of stowaway amphibians and reptiles (Conant, 1945).

\section{REFERENCES}

Allain, S.J.R., Smith, L.T. \& Miller, G.J. (2017). Introduced non-native amphibians and reptiles in Cambridgeshire 2010-2016. Nature in Cambridgeshire 59: 44-50.

Banks, B. (1985). Hyla rubra: a case of illegal immigration. British Herpetological Society Bulletin 12: 43-44.

Bombieri, G., Nanni, V., Delgado, M.D.M., Fedriani, J. M., López-Bao, J.V., Pedrini, P. \& Penteriani, V. (2018). Content analysis of media reports on predator attacks on humans: toward an understanding of human risk perception and predator acceptance. Bioscience 68: 577-584.

CABI (2019). Invasive species compendium. Lampropeltis californiae. https://www.cabi.org/isc/datasheet/120356 (accessed October 2020)

Ceríaco, L.M. (2012). Human attitudes towards herpetofauna: The influence of folklore and negative values on the conservation of amphibians and reptiles in Portugal. Journal of Ethnobiology and Ethnomedicine 8: 8.

Chapple, D.G., Whitaker, A.H., Chapple, S.N., Miller, K.A. \& Thompson, M.B. (2013). Biosecurity interceptions of an invasive lizard: origin of stowaways and human-assisted spread within New Zealand. Evolutionary Applications 6: 324-339.

Clemens, D.J. \& Allain, S.J.R. (2020). First evidence of Fogo Island skink (Chioninia fogoensis) introduction to the island of Madeira. Herpetological Bulletin 152: 40-41.

Conant, R. (1945). More reptiles in cork shipments. Copeia 1945: 233.

Kiesecker, J.M. (2011). Global stressors and the global decline of amphibians: tipping the stress immunocompetency axis. Ecological Research 26: 897-908.

Knight, A.J. (2008). "Bats, snakes and spiders, Oh my!" How aesthetic and negativistic attitudes, and other concepts predict support for species protection. Journal of Environmental Psychology 28: 94-103.

Manchester, S.J. \& Bullock, J.M. (2000). The impacts of nonnative species on UK biodiversity and the effectiveness of control. Journal of Applied Ecology 37: 845-864.

Mattison, C. (1986). Yes, We Have No Banana Frogs! British Herpetological Society Bulletin 18:20.

Oreska, M. P. \& Aldridge, D.C. (2011). Estimating the financial costs of freshwater invasive species in Great Britain: a standardized approach to invasive species costing. Biological Invasions 13: 305-319.

Pyšek, P., Jarošík, V. \& Pergl, J. (2011). Alien plants introduced by different pathways differ in invasion success: unintentional introductions as a threat to natural areas. PloS ONE 6: e24890.

Smales, L.R., Allain, S.J.R., Wilkinson, J.W. \& Harris, E. (2020). A new species of Pseudoacanthocephalus (Acanthocephala: Echinorhynchidae) from the guttural toad, Sclerophrys gutturalis (Bufonidae), introduced into Mauritius, with comments on the implications of the 
introductions of toads and their parasites into the United Kingdom. Journal of Helminthology 94: e119.

Smith, M.A. (1949). The midwife toad (Alytes obstetricans) in England. British Journal of Herpetology 1: 55-56.

Traill, L.W., Bradshaw, C.J. \& Brook, B.W. (2007). Minimum viable population size: a meta-analysis of 30 years of published estimates. Biological Conservation 139: 159166.

Wanless, F.R. (1977). On the occurrence of the scorpion Euscorpius flavicaudis (DeGeer) at Sheerness Port, Isle of Sheppey, Kent. Bulletin of the British Arachnological Society 4: 74-76.
While, G.M., Williamson, J., Prescott, G., Horváthová, T., Fresnillo, B., Beeton, N.J., Halliwell, B., Michaelides, S. \& Uller, T. (2015). Adaptive responses to cool climate promotes persistence of a non-native lizard. Proceedings of the Royal Society B: Biological Sciences 282: 20142638. Young, H.S., Parker, I.M., Gilbert, G.S., Guerra, A.S. \& Nunn, C.L. (2017). Introduced species, disease ecology, and biodiversity-disease relationships. Trends in Ecology \& Evolution 32: 41-54.

Accepted: 22 October 2020

Please note that the Supplementary Material for this article is available online via the Herpetological Bulletin website: https://thebhs.org/publications/the-herpetological-bulletin/issue-number-154-winter-2020 